\title{
Salirhabdus euzebyi gen. nov., sp. nov., a Gram-positive, halotolerant bacterium isolated from a sea salt evaporation pond
}

Correspondence Milton S. da Costa milton@ci.uc.pt

\author{
Luciana Albuquerque, ${ }_{1}^{1}$ Igor Tiago, ${ }^{1}$ Fred A. Rainey, ${ }^{2}$ Marco Taborda, ${ }^{1}$ \\ M. Fernanda Nobre, ${ }^{1}$ António Veríssimo ${ }^{1}$ and Milton S. da Costa ${ }^{3}$ \\ ${ }^{1}$ Centro de Neurociências e Biologia Celular, Departamento de Zoologia, \\ Universidade de Coimbra, 3004-517 Coimbra, Portugal \\ ${ }^{2}$ Department of Biological Sciences, Louisiana State University, Baton Rouge, LA 70803, USA \\ ${ }^{3}$ Departamento de Bioquímica, Universidade de Coimbra, 3001-401 Coimbra, Portugal
}

\begin{abstract}
A low-G $+C$, Gram-positive bacterium, designated CVS-14 ${ }^{\top}$, was recovered from a sea salt evaporation pond on the island of Sal in the Cape Verde Archipelago. This organism was catalase- and oxidase-positive. Cells were motile, spore-forming aerobic rods, with an optimum growth temperature of about $35-40^{\circ} \mathrm{C}$ and optimum $\mathrm{pH}$ between 7.0 and 8.5. Optimal growth occurred in media containing 4-6\% $(\mathrm{w} / \mathrm{v}) \mathrm{NaCl}$, although the organism was able to grow in medium without added $\mathrm{NaCl}$ and in medium containing $16 \% \mathrm{NaCl}$. The cell-wall peptidoglycan was of A1 $\gamma$ type and the major respiratory quinone was menaquinone 7 (MK-7). Major fatty acids were iso-15: 0 , anteiso-15:0, iso-17:0 and anteiso-17:0. The DNA G +C content was 37.0 mol\%. Phylogenetic analysis of the $16 \mathrm{~S}$ rRNA gene sequence indicated that strain CVS $-14^{\top}$ formed a distinct new branch within the radiation of the moderately halophilic bacilli group, forming a separate lineage from species of the genera Salinibacillus, Paucisalibacillus, Oceanobacillus, Lentibacillus and Virgibacillus. Strain CVS $-14^{\top}$ showed $16 \mathrm{~S}$ rRNA gene pairwise similarity values of $\sim 95 \%$ with species of the genus Salinibacillus. On the basis of morphological, physiological, chemotaxonomic and phylogenetic characteristics, strain CVS $-14^{\top}$ is considered to represent a novel species in a new genus, for which the name Salirhabdus euzebyi gen. nov., sp. nov. is proposed. The type strain is CVS $-14^{\top}\left(=\right.$ LMG $22839^{\top}=$ CIP $\left.108577^{\top}\right)$.
\end{abstract}

Gram-positive rod-shaped, aerobic or facultatively anaerobic, spore-forming bacteria that grow optimally in media containing $\mathrm{NaCl}$ are currently assigned to 19 genera with similar characteristics and close phylogenetic relationships (Nunes et al., 2006). During a survey of bacterial diversity present in sea salt evaporation pond samples collected on the island of Sal in the Cape Verde Archipelago, several slightly halophilic Gram-positive bacteria were isolated and characterized further. One of these isolates shared several physiological and biochemical characteristics with other species of halophilic bacilli and was phylogenetically most closely related to species of the genus Salinibacillus (Ren \& Zhou, 2005). However, this organism had a distinctly lower $\mathrm{NaCl}$ requirement for optimal growth and a distinctive fatty acid content. Furthermore, 16S rRNA gene sequence analysis indicated that this organism represents a novel

The GenBank/EMBL/DDBJ accession number for the 16S rRNA gene sequence of strain CVS-14 $4^{\top}$ is AM292417.

A figure showing the effect of salt on the growth of strain CVS-14 ${ }^{\top}$ and a monodimensional TLC of polar lipids of strain CVS-14 ${ }^{\top}$ are available with the online version of this paper. phylogenetic lineage within the radiation of the genus Bacillus and related genera. Based on morphological, physiological, chemotaxonomic and phylogenetic characteristics, we describe a novel species in a new genus to accommodate strain CVS- $14^{\mathrm{T}}$.

Strain CVS- $14^{\mathrm{T}}$ was isolated from a sea salt evaporation pond on solid R3A-V medium (Tiago et al., 2006), pH 7.0, containing $2 \% \mathrm{NaCl}(\mathrm{w} / \mathrm{v})$. Soil samples $(3 \mathrm{~g})$ were resuspended on sterile blenders with sterile $2 \% \mathrm{NaCl}$. One drop of the homogenate was spread on $\mathrm{R} 3 \mathrm{~A}-\mathrm{V}$ agar plates. These preparations were incubated at $37^{\circ} \mathrm{C}$ for up 5 days. The R3A-V medium contained the following components $\left(1^{-1}\right)$ : $1.0 \mathrm{~g}$ yeast extract (Difco), $1.0 \mathrm{~g}$ proteose peptone (Difco no. 3), $1.0 \mathrm{~g}$ Casamino acids, 1.0 g glucose, $0.6 \mathrm{~g} \mathrm{~K}_{2} \mathrm{HPO}_{4}, 0.1 \mathrm{~g} \mathrm{MgSO}_{4} .7 \mathrm{H}_{2} \mathrm{O}, 0.05 \mathrm{~g} \mathrm{Na}$ pyruvate, $15.0 \mathrm{~g}$ agar (Difco), $50 \mathrm{ml}$ of a 10 -fold concentrated macronutrients solution, $5 \mathrm{ml}$ of a 100 -fold concentrated trace elements solution and $100 \mathrm{ml}$ of $1 \mathrm{M}$ phosphate buffer (pH 7.0); macronutrients, trace elements and the phosphate buffer were autoclaved separately and added to the cooled R3A agar. The 10-fold concentrated macronutrients 
solution contained $\left(\mathrm{l}^{-1}\right): 1.0 \mathrm{~g}$ nitrilotriacetic acid, $0.6 \mathrm{~g}$ $\mathrm{CaSO}_{4} .2 \mathrm{H}_{2} \mathrm{O}, 1.0 \mathrm{~g} \mathrm{MgSO}_{4} .7 \mathrm{H}_{2} \mathrm{O}, 0.8 \mathrm{~g} \mathrm{NaCl}, 1.03 \mathrm{~g}$ $\mathrm{KNO}_{3}, 6.89 \mathrm{~g} \mathrm{NaNO}_{3}$ and $1.11 \mathrm{~g} \mathrm{NaHPO}_{4}$. The 100 -fold concentrated trace elements solution contained $\left(\mathrm{l}^{-1}\right): 0.22 \mathrm{~g}$ $\mathrm{MnSO}_{4} \cdot \mathrm{H}_{2} \mathrm{O}, 0.05 \mathrm{~g} \mathrm{ZnSO}_{4} .7 \mathrm{H}_{2} \mathrm{O}, 0.05 \mathrm{~g} \mathrm{H}_{3} \mathrm{BO}_{3}, 0.0025 \mathrm{~g}$ $\mathrm{CuSO}_{4} \cdot 5 \mathrm{H}_{2} \mathrm{O}, 0.0025 \mathrm{~g} \mathrm{Na}_{2} \mathrm{MoO}_{4} \cdot 2 \mathrm{H}_{2} \mathrm{O}$ and $0.0046 \mathrm{~g}$ $\mathrm{CoCl}_{2} \cdot 6 \mathrm{H}_{2} \mathrm{O}$.

Despite repeated attempts to isolate additional strains, only one isolate was obtained. Cultures were purified by subculturing on the same medium and maintained at $-70{ }^{\circ} \mathrm{C}$ in Degryse medium 162 containing $3 \% \mathrm{NaCl}$ and $15 \%(\mathrm{w} / \mathrm{v})$ glycerol (Degryse et al., 1978). The organism was also routinely cultured in Degryse medium 162 containing $5 \%$ $\mathrm{NaCl}$ at $37^{\circ} \mathrm{C}$ for up to 5 days, unless stated otherwise (Albuquerque et al., 2005). Paucisalibacillus globulus $\mathrm{B} 22^{\mathrm{T}}$ was used for comparative purposes; the type strains of Salinibacillus kushneri and Salinibacillus aidingensis were not available from the Japanese Collection of Microorganisms (JCM).

The growth temperature range of strain CVS- $14^{\mathrm{T}}$ was examined in liquid medium in a reciprocal water bath shaker between 10 and $55^{\circ} \mathrm{C}$; the $\mathrm{pH}$ range for growth was determined at $37^{\circ} \mathrm{C}$ in the same medium buffered at $\mathrm{pH}$ values between 5.5 and 10.5 by using 20 mM MES, Tris and CAPSO (Sigma). The $\mathrm{NaCl}$ range for growth was determined in liquid medium without additional $\mathrm{NaCl}$ and with up to $20 \% \mathrm{NaCl}$. Enzymic activities were determined by using the API ZYM system (bioMérieux) at $37^{\circ} \mathrm{C}$. Anaerobic growth was assessed in solidified Degryse medium with $5.0 \% \mathrm{NaCl}$ and $1.0 \mathrm{~g} \mathrm{KNO}_{3} \mathrm{l}^{-1}$ in anaerobic chambers (GENbox anaer; bioMérieux). Single carbon source assimilation tests were performed in a defined medium composed of Degryse basal salts containing $5.0 \% \mathrm{NaCl}, 0.1 \mathrm{~g}$ yeast extract $\mathrm{l}^{-1}, 0.5 \mathrm{~g}$ ammonium sulfate $\mathrm{l}^{-1}, 2.0 \mathrm{~g}$ single carbon sources $1^{-1}$ and $2 \%$ deionized water-washed agar (Oxoid). Cultures $(24 \mathrm{~h})$ from plates were resuspended in the basal salts medium (turbidity equivalent to a McFarland no. 1 standard) and a single drop of the suspension was placed on plates, each of which contained a single carbon source. Growth was examined visually for up to 5 days. Negative control plates did not include a carbon source. Carbon source assimilation profiles were also investigated in liquid media with the same composition indicated above, but this proved unsuccessful owing to the absence of growth or clumping of cells. Acid production from carbohydrates was determined by using the API $50 \mathrm{CH}$ system (bioMérieux) according to the manufacturer's instructions, with API 50 $\mathrm{CHB} / \mathrm{E}$ medium containing $5.0 \% \mathrm{NaCl}$. Results were recorded after $24 \mathrm{~h}, 48 \mathrm{~h}$ and 5 days incubation at $37^{\circ} \mathrm{C}$.

Peptidoglycan analysis was performed according to the method of Schleifer \& Kandler (1972) and Schleifer (1985); respiratory quinone analysis was performed according to the method of Tindall (1989). Cultures for fatty acid analyses were grown on solidified Degryse medium 162 containing $5 \% \mathrm{NaCl}$ incubated in sealed plastic bags submerged in a water-bath at $37^{\circ} \mathrm{C}$ for $48 \mathrm{~h}$. Fatty acid methyl esters were extracted as described by Moreira et al. (2000). Identification and quantification of fatty acid methyl esters, as well as numerical analysis of the fatty acid profiles, were performed by using the standard MIS Library Generation Software (Microbial ID). Polar lipid analyses were performed as described by Prado et al. (1988).

The $\mathrm{G}+\mathrm{C}$ content of the DNA was determined by HPLC as described by Mesbah et al. (1989). The 16S rRNA gene was amplified by PCR and sequenced as described by Rainey et al. (1996). Phylogenetic analyses were performed using the ARB software package (Ludwig et al., 2004) and a phylogenetic tree was constructed by using the neighbourjoining (Saitou \& Nei, 1987) algorithm. Tree topologies were evaluated by performing bootstrap analysis (Felsenstein, 1985) of 1000 resamplings of the data set.

Comparative analyses of $1479 \mathrm{nt}$ positions of the 16S rRNA gene sequence of strain CVS- $14^{\mathrm{T}}$ with those of other lineages within the low-G $+\mathrm{C}$ Gram-positive bacteria showed that the new isolate clustered with other moderately halophilic bacilli. Strain CVS- $14^{\mathrm{T}}$ showed highest $16 \mathrm{~S}$ rRNA gene sequence similarities to species of the genus Salinibacillus, $95.7 \%$ to $S$. aidingensis $\mathrm{JCM} 12389^{\mathrm{T}}$ and $95.14 \%$ to $S$. kushneri JCM $12390^{\mathrm{T}}$. The next closest relative was P. globulus B22 ${ }^{\mathrm{T}}$ with $94.9 \% \quad 16 \mathrm{~S}$ rRNA gene sequence similarity. Similarity values in the range $90.3-95.2 \%$ were found to members of the genera Lentibacillus, Oceanobacillus and Virgibacillus. Strain CVS- $14^{\mathrm{T}}$ grouped with species of the genus Salinibacillus but the branching point was not fully supported, with a bootstrap value of $69 \%$ (Fig. 1). The G +C content of the DNA of strain CVS- $14^{\mathrm{T}}$ was $37.0 \mathrm{~mol} \%$.

Strain CVS- $14^{\mathrm{T}}$ formed non-pigmented colonies and Grampositive, motile, long rod-shaped cells $(0.3-0.4 \mu \mathrm{m}$ in width by $2.9-8.6 \mu \mathrm{m}$ in length) with oval endospores at a terminal position within a swollen sporangium, giving the cells the appearance of spermatozoids (Fig. 2). The optimum $\mathrm{NaCl}$ concentration for growth was $4-6 \%$, but good growth occurred both in the absence of additional $\mathrm{NaCl}$ and in medium containing up to $16 \% \mathrm{NaCl}$ (see Supplementary Fig. S1 in IJSEM Online). Species belonging to the genus Salinibacillus, in contrast with strain CVS-14 ${ }^{\mathrm{T}}$, require $1 \%$ $\mathrm{NaCl}$ for growth and have higher optimum and maximum $\mathrm{NaCl}$ ranges for growth (Table 1).

Strain CVS- $14^{\mathrm{T}}$ was oxidase-, catalase- and DNase-positive and hydrolysed gelatin, hippurate and Tweens 20, 40, 60 and 80. Aesculin, arbutin, casein, elastin, starch and xylan were not hydrolysed. Yeast extract was required for growth on single carbon sources. Strain CVS- $14^{\mathrm{T}}$ assimilated carbohydrates, polyols, organic acids and amino acids. Acid was produced from several carbohydrates. Nitrate and nitrite were reduced. Anaerobic growth in the presence of nitrate was not observed.

Strain CVS- $14^{\mathrm{T}}$ had a cell-wall type A1 $\gamma$ peptidoglycan with meso-diaminopimelic acid as the diagnostic diamino acid, which is common in the majority of endospore-forming 


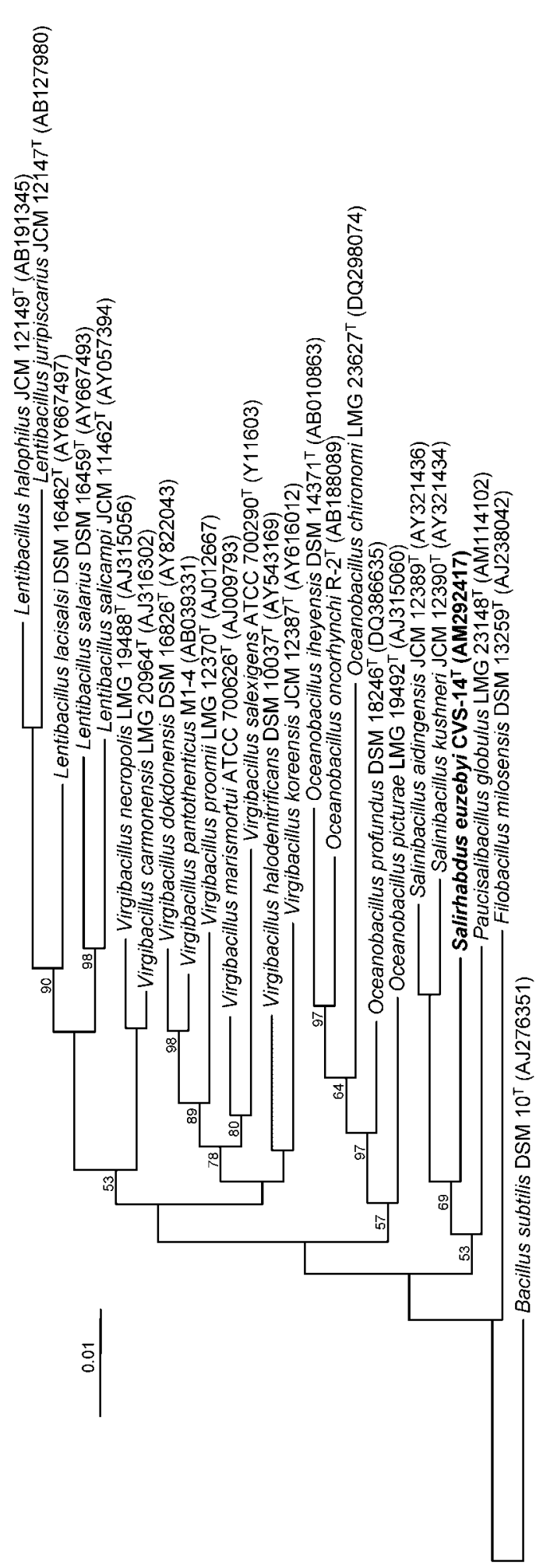

Fig. 1. Phylogenetic dendrogram based on a comparison of the $16 \mathrm{~S}$ rRNA gene sequences of strain CVS $-14^{\top}$ and its closest phylogenetic relatives. The tree was created by using the neighbour-joining method. Numbers on the tree indicate bootstrap support (\%), derived from 1000 replications. Bar, 1 inferred nucleotide substitution per $100 \mathrm{nt}$.

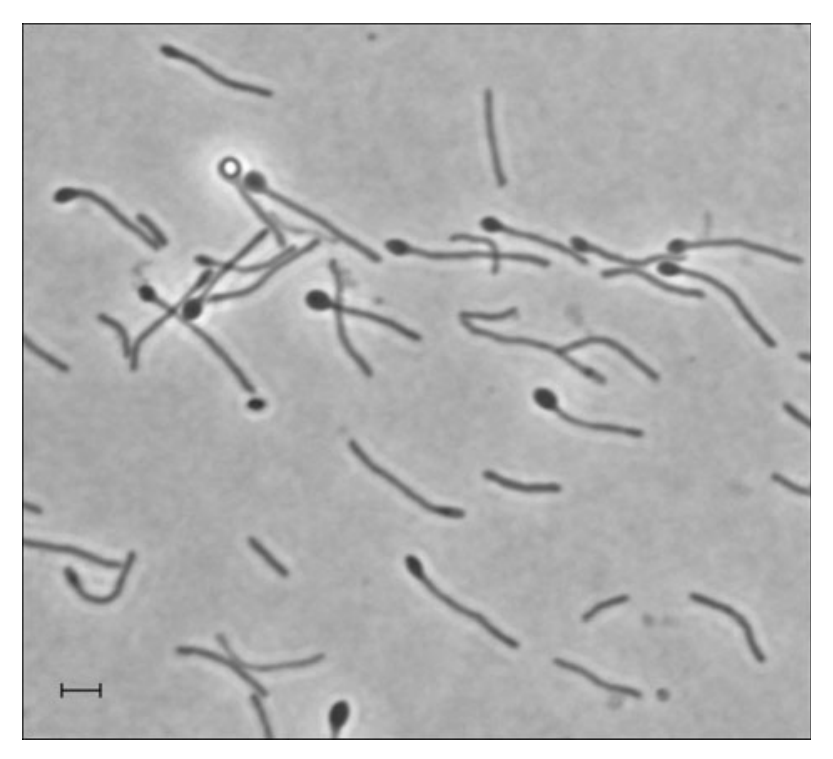

Fig. 2. Phase-contrast micrograph of cells of strain CVS $-14^{\top}$ cultivated for $24 \mathrm{~h}$ showing elongated cells and terminal spores within a swollen sporangium. Bar, $2 \mu \mathrm{m}$.

Gram-positive rods. The polar lipid pattern on TLC revealed the presence of diphosphatidylglycerol, phosphatidylethanolamine and phosphatidylglycerol (see Supplementary Fig. S2 in IJSEM Online). The major respiratory lipoquinone was menaquinone 7 (MK-7). The fatty acid profile of strain CVS-14 ${ }^{\mathrm{T}}$, as well as those of species of the genus Salinibacillus, was dominated by branched fatty acids, namely iso-15:0, anteiso- $15: 0$, iso-17:0 and anteiso17:0 (Table 2). However, strain CVS- $14^{\mathrm{T}}$ and species of the genus Salinibacillus could be distinguished based on the relative amounts of these fatty acids. Moreover, strain CVS-14 ${ }^{\mathrm{T}}$ possessed acyl compounds such as $16: 1 \omega 7 \mathrm{c}$ alcohol, iso-17: $1 \omega 10 c$ and summed feature 4 (iso-17: $1 \mathrm{I}$ and/or anteiso-17:1 B) that are not detected in the type strains of the two other recognized species of the genus Salinibacilus (Ren \& Zhou, 2005) or in the type strain of P. globulus. Strain CVS-14 ${ }^{\mathrm{T}}$ could also be distinguished from other slightly halophilic endospore-forming bacilli (Tables 1 and 2).

Despite similar characteristics and phylogenetic relatedness to several moderately halophilic bacilli, strain CVS-14 ${ }^{\mathrm{T}}$ could be clearly distinguished from the type strains of species of the related genera Paucisalibacillus and Salinibacillus, namely based on $\mathrm{NaCl}$ requirements for optimal growth, fatty acid content as well as other phenotypic characteristics and, for the genus Paucisalibacillus, a different cell-wall type.

On the basis of these findings, strain CVS- $14^{\mathrm{T}}$ is considered to represent a novel species in a new genus, for which the name Salirhabdus euzebyi gen. nov., sp. nov. is proposed. 
Table 1. Phenotypic characteristics that differentiate strain CVS-14 ${ }^{\top}$ from the type strains of species of the genera Salinibacillus, Paucisalibacillus and other related genera

Taxa: 1, strain CVS-14 ${ }^{\mathrm{T}}$; 2, Salinibacillus (data from the two recognized species of the genus Salinibacillus from Ren \& Zhou, 2005); 3, Paucisalibacillus globulus $\mathrm{B} 22^{\mathrm{T}}$ (data from Nunes et al., 2006); 4, Virgibacillus (data from 10 recognized species of the genus Virgibacillus from Yoon et al., 2005; Lee et al., 2006); 5, Oceanobacillus (data from five recognized species of the genus Oceanobacillus from Lu et al., 2001; Lee et al., 2006; Raats \& Halpern, 2007; Kim et al., 2007); 6, Lentibacillus (data from six recognized species of the genus Lentibacillus from Pakdeeto et al., 2007). +, Positive; -, negative; v, variable; ND, not determined.

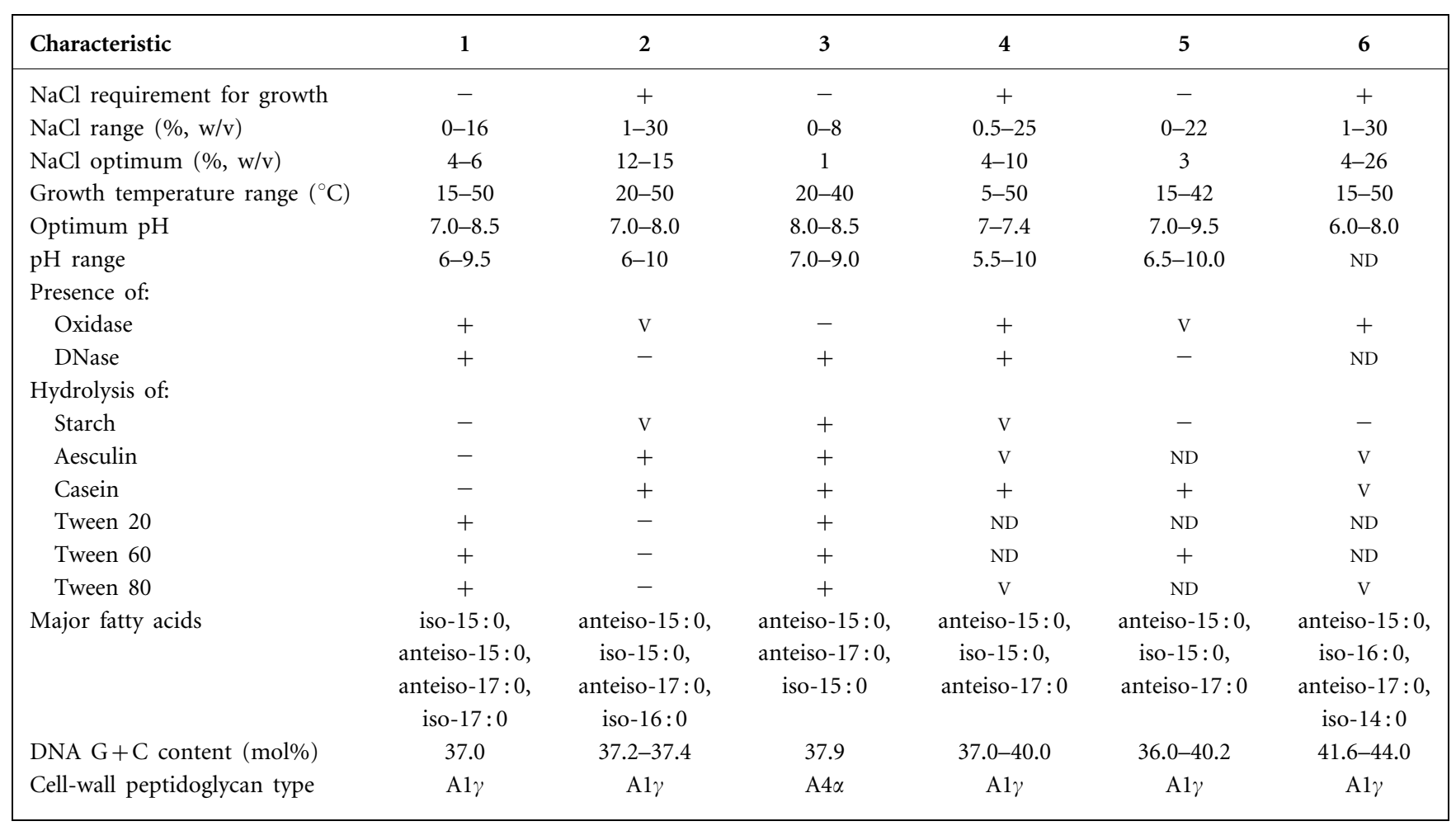

\section{Description of Salirhabdus gen. nov.}

Salirhabdus [Sa.li.rhab'dus. L. n. sal salis salt; N.L. fem. n. rhabdus (from Gr. fem. n. rhabdos) a rod, wand; N.L. fem. n. Salirhabdus a rod that grows in salt].

Forms rod-shaped cells that stain Gram-positive and form terminal spores within a swollen sporangium. Strictly aerobic. Oxidase- and catalase-positive. $\mathrm{NaCl}$ is not required for growth but the addition of $\mathrm{NaCl}$ to the culture medium improves growth. Cell-wall peptidoglycan is of the A $1 \gamma$ type. Diphosphatidylglycerol, phosphatidylethanolamine and phosphatidylglycerol are the major polar lipids. Major respiratory quinone is MK-7. Fatty acids are predominantly saturated branched chain. The genus belongs to the family Bacillaceae. The type species is Salirhabdus euzebyi.

\section{Description of Salirhabdus euzebyi sp. nov.}

Salirhabdus euzebyi (eu.ze.by'i. N.L. gen. masc. n. euzebyi of Euzéby, in honour of the French bacteriologist Jean P. Euzéby).

Has the following characteristics in addition to those given for the genus. Forms rod-shaped cells $0.3-0.4 \mu \mathrm{m}$ in width and 2.9-8.6 $\mu \mathrm{m}$ in length. Cells are motile. Oval endospores are formed at a terminal position in a swollen sporangium. Colonies are cream-pigmented on Degryse medium 162 with $5 \% \mathrm{NaCl}$. The optimum growth temperature is $\sim 37-45^{\circ} \mathrm{C}$; growth does not occur at 10 or $55^{\circ} \mathrm{C}$. The optimum $\mathrm{pH}$ is between 7.0 and 8.5; growth does not occur at $\mathrm{pH} 5.5$ or $\mathrm{pH}$ 10.0. Grows in media without added salt and in media containing $16 \% \mathrm{NaCl}$; the optimum $\mathrm{NaCl}$ concentration for growth is between 4 and $6 \%$. Growth does not occur in media containing $20 \% \mathrm{NaCl}$. The major fatty acids are iso-15:0, anteiso-15:0, iso-17:0 and anteiso$17: 0$; iso- $14: 0,15: 0,16: 1 \omega 7 c$ alcohol, iso- $16: 0,16: 0$, iso-17: $1 \omega 10 c$, summed feature $4,17: 0$, iso-18:0 and 19:0 are present as minor components. Yeast extract or growth factors are required for growth. Denitrifies. Gelatin, hippurate and Tweens 20, 40, 60 and 80 are hydrolysed, but aesculin, arbutin, casein, elastin, starch and xylan are not. Positive for DNase, alkaline phosphatase, leucine arylamidase, $\alpha$-chymotrypsin and $\beta$-glucosidase; negative for esterase (C4), esterase lipase (C8), lipase (C14), valine arylamidase, cystine arylamidase, trypsin, acid phosphatase, naphthol-AS-BI-phosphohydrolase, $\alpha$-galactosidase and $\beta$-galactosidase. Glucose, mannose, fructose, D-arabinose, xylose, sucrose, maltose, trehalose, cellobiose, melibiose, 
Table 2. Fatty acid content (\%) of strain CVS-14 ${ }^{\top}$ and the type strains of species of the genera Salinibacillus, Paucisalibacillus and other related genera

Taxa: 1, strain CVS-14 ${ }^{\mathrm{T}}$; 2, Salinibacillus (data from the two recognized species of the genus Salinibacillus from Ren \& Zhou, 2005); 3, Paucisalibacillus globulus $\mathrm{B} 22^{\mathrm{T}}$ (data from Nunes et al., 2006); 4, Virgibacillus (data from ten recognized species of the genus Virgibacillus from Yoon et al., 2005; Lee et al., 2006); 5, Oceanobacillus (data from five recognized species of the genus Oceanobacillus from Lu et al., 2001; Lee et al., 2006; Raats \& Halpern, 2007; Kim et al., 2007); 6, Lentibacillus (data from four recognized species of the genus Lentibacillus from Pakdeeto et al., 2007). Data are mean \pm SD percentages of each fatty acid. - , Not detected; tr, trace $(<0.5 \%)$.

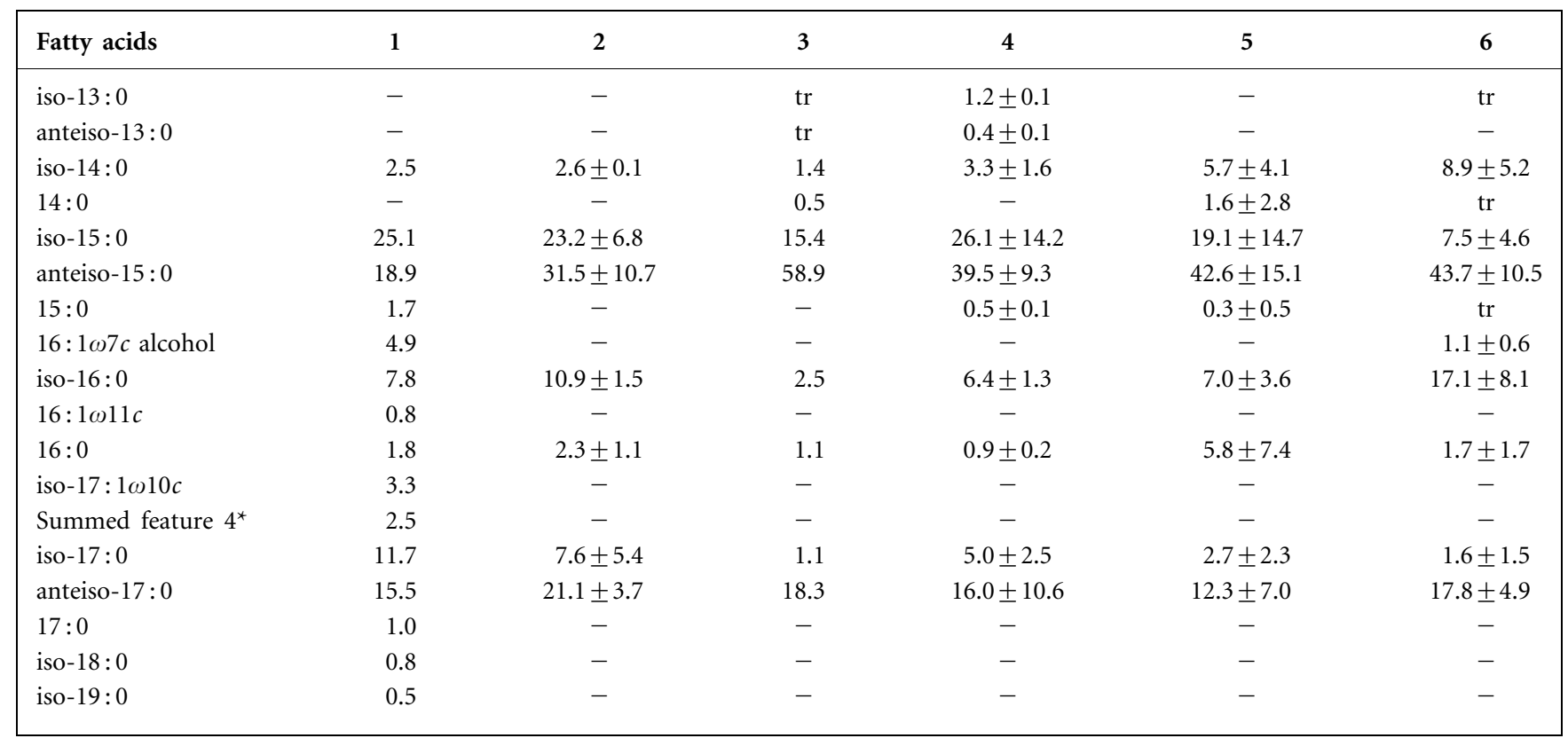

${ }^{\star}$ A summed feature represents groups of two or three fatty acids that could not be separated by GLC with the MIDI system. Summed feature 4 comprises iso-17:1 I and/or anteiso-17:1 B.

L-rhamnose, raffinose, ribitol, xylitol, sorbitol, mannitol, myo-inositol, succinate, 2-oxoglutarate, lactate, malate, pyruvate, cysteine, histidine, lysine, proline, arginine, serine, valine and ornithine are assimilated, but galactose, sorbose, L-arabinose, ribose, lactose, melezitose, glycerol, citrate, acetate, aspartate, glutamate, alanine, asparagine, phenylalanine, glycine, isoleucine, methionine, glutamine and threonine are not. Acid is produced from glycerol, ribose, glucose, fructose, mannose, L-sorbose, methyl $\alpha$-Dmannopyranoside, methyl $\alpha$-D-glucopyranoside, trehalose, tagatose, potassium 2-ketogluconate and potassium 5-ketogluconate, but not from erythritol, D-arabinose, L-arabinose, D-xylose, L-xylose, adonitol (ribitol), methyl $\beta$-Dxylopyranoside, galactose, rhamnose, dulcitol (galactitol), inositol, mannitol, sorbitol, methyl $\alpha$-D-mannopyranoside, amygdalin, arbutin, aesculin, salicin, cellobiose, maltose, lactose, melibiose, sucrose, inulin, melezitose, raffinose, starch, glycogen, xylitol, gentiobiose, turanose, lyxose, D-fucose, L-fucose, D-arabitol, L-arabitol or potassium gluconate. The $\mathrm{G}+\mathrm{C}$ content of the DNA is $37.0 \mathrm{~mol} \%$ (HPLC method).

The type strain, CVS-14 ${ }^{\mathrm{T}}\left(=\mathrm{LMG} 22839^{\mathrm{T}}=\mathrm{CIP} 108577^{\mathrm{T}}\right)$, was isolated from a sea salt evaporation pond on the island of Sal in the Cape Verde Archipelago.

\section{Acknowledgements}

The research was funded, in part, by Fundação para a Ciência e a Tecnologia (POCI/BIA-BDE/60704/2004), and by the Governor's Biotechnology Initiative of the Louisiana Board of Regents (BOR\#021Moving an Established Marine Biotechnology Program to the Next Level: Natural Product Screening and Development). We would also like to thank José Tiago for sample collection.

\section{References}

Albuquerque, L., Simões, C., Nobre, M. F., Pino, N. M., Battista, J. R., Silva, M. T., Rainey, F. A. \& da Costa, M. S. (2005). Truepera radiovictrix gen. nov., sp. nov., a new radiation-resistant species and the proposal of Trueperaceae fam. nov. FEMS Microbiol Lett 247, 161-169.

Degryse, E., Glansdorff, N. \& Pierard, A. (1978). A comparative analysis of extreme thermophilic bacteria belonging to the genus Thermus. Arch Microbiol 117, 189-196.

Felsenstein, J. (1985). Confidence limits on phylogenies: an approach using the bootstrap. Evolution 39, 783-791.

Kim, Y. G., Choi, D. H., Hyun, S. \& Cho, B. C. (2007). Oceanobacillus profundus sp. nov., isolated from a deep-sea sediment core. Int J Syst Evol Microbiol 57, 409-413.

Lee, J.-S., Lim, J.-M., Lee, K. C., Lee, J.-C., Park, Y.-H. \& Kim, C.-J. (2006). Virgibacillus koreensis sp. nov., a novel bacterium from a salt field and transfer of Virgibacillus picturae to the genus 
Oceanobacillus as Oceanobacillus picturae comb. nov. with emended descriptions. Int J Syst Evol Microbiol 56, 251-257.

Lu, J., Nogi, Y. \& Takami, H. (2001). Oceanobacillus iheyensis gen. nov., sp. nov., a deep-sea extremely halotolerant and alkaliphilic species isolated from a depth of $1050 \mathrm{~m}$ on the Iheya Ridge. FEMS Microbiol Lett 205, 291-297.

Ludwig, W., Strunk, O., Westram, R., Richter, L., Meier, H., Yadhukumar, Buchner, A., Lai, T., Steppi, S. \& other authors (2004). ARB: a software environment for sequence data. Nucleic Acids Res 32, 1363-1371.

Mesbah, M., Premachandran, U. \& Whitman, W. (1989). Precise measurement of the $\mathrm{G}+\mathrm{C}$ content of deoxyribonucleic acid by high-performance liquid chromatography. Int J Syst Bacteriol 39, 159-167.

Moreira, C., Rainey, F. A., Nobre, M. F., da Silva, M. T. \& da Costa, M. S. (2000). Tepidimonas ignava gen. nov., sp. nov., a new chemolithoheterotrophic and slightly thermophilic member of the $\beta$-Proteobacteria. Int J Syst Evol Microbiol 50, 735-742.

Nunes, I., Tiago, I., Pires, A. L., da Costa, M. S. \& Verissimo, A. (2006). Paucisalibacillus globulus gen. nov., sp. nov., a Gram-positive bacterium isolated from potting soil. Int J Syst Evol Microbiol 56, 1841-1845.

Pakdeeto, A., Tanasupawat, S., Thawai, C., Moonmangmee, S., Kudo, T. \& Itoh, T. (2007). Lentibacillus kapialis sp. nov., from fermented shrimp paste in Thailand. Int J Syst Evol Microbiol 57, 364-369.

Prado, A., da Costa, M. S. \& Madeira, V. M. C. (1988). Effect of growth temperature on the lipid composition of two strains of Thermus sp. J Gen Microbiol 134, 1653-1660.
Raats, D. \& Halpern, M. (2007). Oceanobacillus chironomi sp. nov., a halotolerant and facultatively alkaliphilic species isolated from a chironomid egg mass. Int J Syst Evol Microbiol 57, 255-259.

Rainey, F. A., Ward-Rainey, N., Kroppenstedt, R. M. \& Stackebrandt, E. (1996). The genus Nocardiopsis represents a phylogenetically coherent taxon and a distinct actinomycete lineage: proposal of Nocardiopsaceae fam. nov. Int J Syst Bacteriol 46, 1088-1092.

Ren, P. G. \& Zhou, P. J. (2005). Salinibacillus aidingensis gen. nov., sp. nov. and Salinibacillus kushneri sp. nov., moderately halophilic bacteria isolated from a neutral saline lake in Xin-Jiang, China. Int J Syst Evol Microbiol 55, 949-953.

Saitou, N. \& Nei, M. (1987). The neighbor-joining method: a new method for reconstructing phylogenetic trees. Mol Biol Evol 4, 406-425.

Schleifer, K. H. (1985). Analysis of the chemical composition and primary structure of murein. Methods Microbiol 18, 123-156.

Schleifer, K. H. \& Kandler, O. (1972). Peptidoglycan types of bacterial cell walls and their taxonomic implications. Bacteriol Rev 36, 407-477.

Tiago, I., Mendes, V., Pires, C., Morais, P. V. \& Veríssimo, A. (2006). Chimaereicella alkaliphila gen. nov., sp. nov., a Gram-negative alkaliphilic bacterium isolated from a nonsaline alkaline groundwater. Syst Appl Microbiol 29, 100-108.

Tindall, B. J. (1989). Fully saturated menaquinones in the archaebacterium Pyrobaculum islandicum. FEMS Microbiol Lett 60, 251-254.

Yoon, J. H., Kang, S. J., Lee, S. Y., Lee, M. H. \& Oh, T. K. (2005). Virgibacillus dokdonensis sp. nov., isolated from a Korean island, Dokdo, located at the edge of the East Sea in Korea. Int J Syst Evol Microbiol 55, 1833-1837. 